\title{
Validation of Equivalent Circuit Lightning Model of Strike to a Steel Reinforced Structure
}

\author{
Neil Koone \\ System Engineering Department \\ BWXT Pantex LLC \\ Amarillo, TX USA \\ nkoone@pantex.com
}

\author{
Brian Condren \\ System Engineering Department \\ BWXT Pantex LLC \\ Amarillo, TX USA \\ bcondren@pantex.com
}

\begin{abstract}
Lightning strikes to facilities can pose hazards to personnel as well as sensitive processes and equipment. Steel reinforcement in a structure can act as a Faraday cage that can mitigate the effects of lightning. An Equivalent Circuit Lightning Model (ECLM) of a strike's response in a steel reinforced structure has been developed using PSpice (a commercial circuit simulation) where segments of rebar are modeled as inductors and resistors in series. Programs have been written to take architectural information of a steel reinforced structure and create a circuit network that is analogous to the network of reinforcement in a facility. A current waveform representing a severe lightning strike is introduced in the simulated circuit network, and potential differences within the structure are determined using PSpice ${ }^{*}$. In order to validate the ECLM of a steel reinforced structure, high current pulses were injected into two-dimensional steel grids and potential differences across various nodes of the grids were measured. Grids were then simulated using the lightning circuit model to compare with measured potential differences. Validation tests of steel grids provide evidence that the ECLM agrees well with high voltage test measurements.
\end{abstract}

Keywords- lightning, PSpice ${ }^{\oplus}$ equivalent circuit, simulation, validation.

\section{INTRODUCTION}

Lightning surges can damage sensitive equipment as well as pose hazards to sensitive operations. Knowing a structure's response to lightning strike can give insight into ways to mitigate detrimental effects. An Equivalent Circuit Lightning Model (ECLM) has been developed to determine the response of a steel reinforced structure to lightning strike. The model represents the steel reinforcement as circuit elements and a lightning strike as a current injected into the model circuit. The ECLM has been used to model the effects of rebar diameter, rebar spacing, and explosive blast relief discontinuities [1]. And the ECLM has shown good agreement with Finite Difference Time Domain (FDTD) models developed by Sandia National Laboratories [2].

High current tests were performed on five steel grids with varying geometry and materials properties. [3] The ECLM was used to simulate the five grids using the measured current input waveform. Measured voltages across grids were compared to voltage simulations of grids. The ECLM simulations show good agreement with measured voltages.

\section{A. Equivalent Circuit Lightning Model (ECLM)}

The ECLM consists of three sets of programs: an equivalent circuit generator that creates a PSpice netlist that is analogous to a facility's conductive reinforcement, a database that stores and sorts information about the solved equivalent circuit, and visualization tools which allow voltage profiles for the three dimensional structure to be displayed and evaluated.

The equivalent circuit generator produces a PSpice ${ }^{\circledR}$ netlist containing architectural information about steel reinforced construction. Each segment of reinforcement is modeled as an inductor and resistor in series. Rebar diameter and spacing are used to calculate self-inductance and resistance of sections of rebar between junctures. The circuit elements representing the rebar segments are connected in an analogous fashion to the construction of the facility.

Once the circuit network representing the steel reinforced structure is developed by the equivalent circuit generator, a current waveform is injected into the simulated network at a desired location and PSpice ${ }^{(1)}$ is used to solve the circuit network. Figure 1 shows an injected current waveform used to simulate lightning. The values for voltage at each node

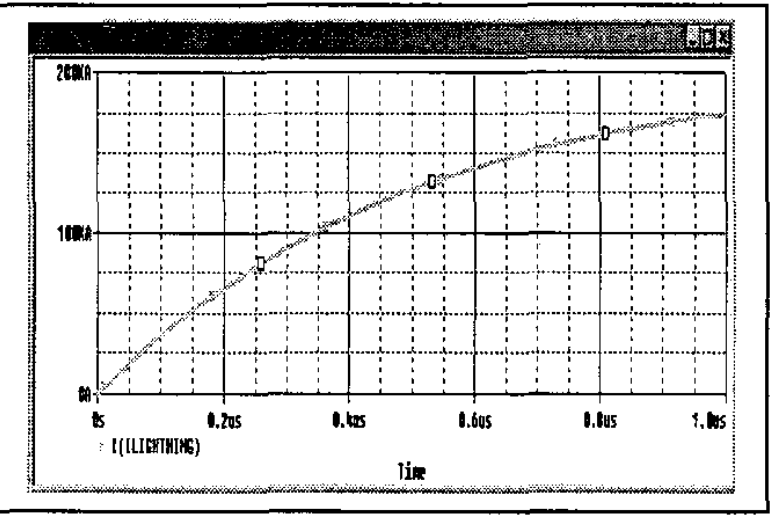

Figure 1. Simulated current input representing lightning 
intersection between horizontal and vertical rebar are extracted using a program to parse the data and save the data into a database. Data is obtained for every node at several time steps for the duration of the simulation. By querying the database, the location, value, and time of the maximum voltage can be determined. Power and current data is also available for each circuit element.

To easily view information from the database, a visualization tool was created. The voltage at each node is displayed on 3D OpenGL ${ }^{(B)}$ model of the facility. Figure 2 shows a grayscale image of the maximum voltage profile for a lightning strike to a generic $20^{\prime} \times 25^{\prime} \times 15^{\prime}$ double layer steel reinforced structure with 6" spacing and \#6 rebar. In this case, the current waveform is injected into the center of a U-shaped discontinuity between three of the facility's walls and the ceiling of a facility. The time slice chosen is that in which the maximum voltage occurs for any particular node. Animations of voltage within a facility are also possible to display.

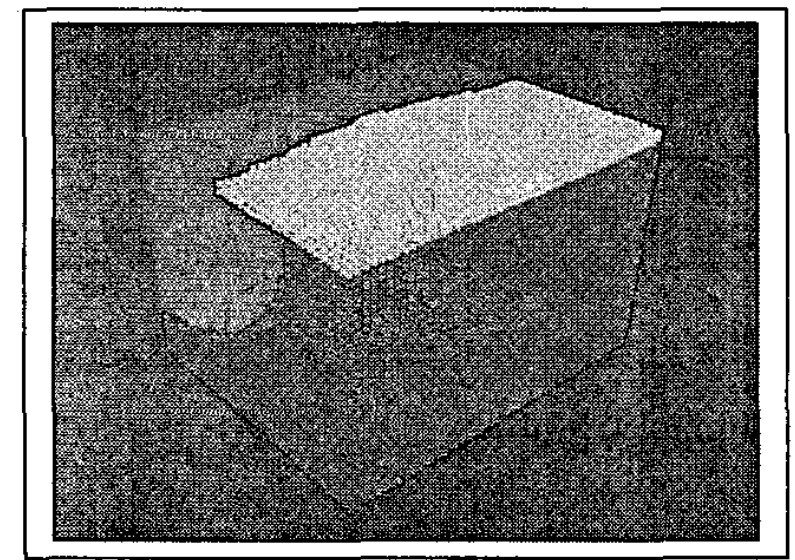

Figure 2. Visualization tool image of maximum voltage profile of lightning strike to a roof which is discontinuous with three walls.

\section{MODEL VALIDATION}

High voltage testing of steel grids was used to validate the Equivalent Lightning Circuit Model. The ECLM relies on several assumptions. They are: rebar segments can be modeled as inductors and resistors in series, a lightning strike can be represented as a current waveform in PSpice, and elements that represent rebar segments that are connected in a similar fashion to the structure of the facility yield comparable voltage and current distributions to that of an actual facility due to a lightning strike.

To prove that these assumptions were valid, high current pulses with a measured profile were injected into steel grids with known geometry and materials properties. The potential difference across the grid was measured as a result of the current pulses injected into the grid. The grid was simulated using the ECLM developed for this project using the actual measured current profile from the test. Potential differences across the grid test points were determined using the simulation. Simulated voltages were compared to measure voltages. A diagram and photo of the test set-up are found in Figures 3 and 4.

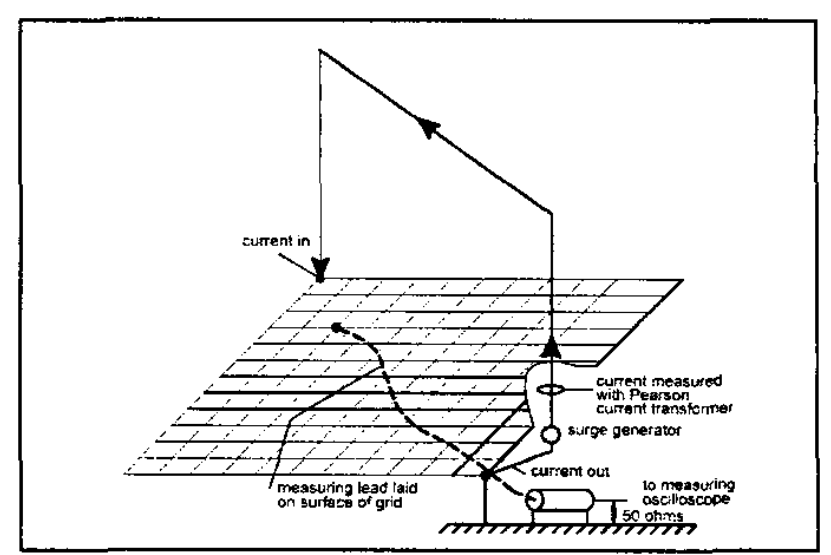

Figure 3. Diagram of Steel Grid Test Set-Up

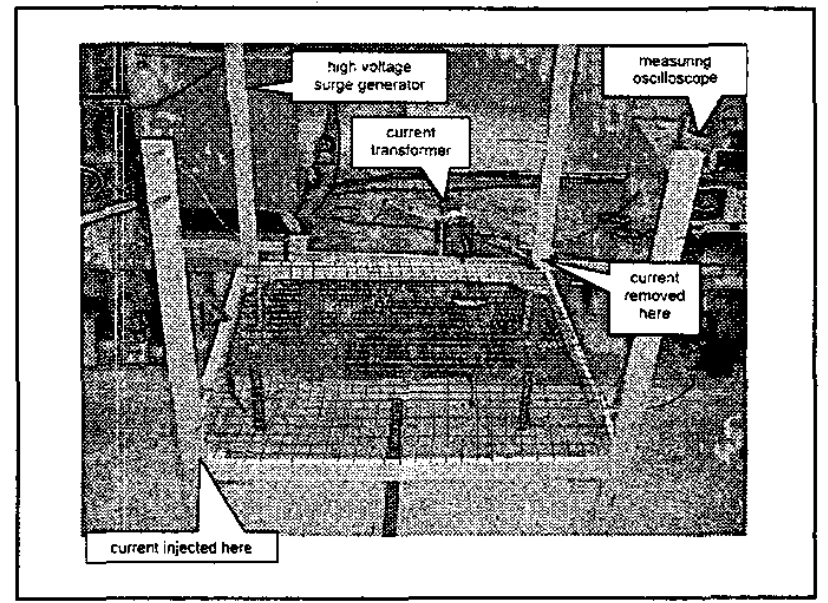

Figure 4. Photograph of Steel Grid Test Set-Up

A series of current injection measurements were made on various types of steel grids in order to provide data against which analytical predictions of current division and grid inductance could be made by BWXT Pantex personnel [3]. Testing was performed at Lightning Technology Inc.'s High Voltage Laboratory in Pittsfield, MA over September 10-12, 2003. A total of 5 steel grids were tested in both low and high current tests.

\section{A. GRIDS TESTED}

The grids tested were those specified by BWXT Pantex and described on Table I. All measured 48 inches by 48 inches.

\section{B. METHODS OF TEST}

The grids were supported by a non-conductive jig illustrated on Figure 1. Current from one of two surge generators was injected into one corner of the grid and removed from the diagonal corner. Injected currents were measured by a Pearson current transformer with the output from the 
transformer displayed on a digital oscilloscope. Voltage was measured with a lead placed on top of the grid, as illustrated on Figure 3; this being found to be the method best suited to display the inherent properties of the grid.

TABLE I. TEST GRID INFORMATION

\begin{tabular}{|c|c|c|c|c|c|}
\hline & Grid $\# 1$ & Grid $\# 2$ & Grid $\# 3$ & Grid $\# 4$ & Grid \#5 \\
\hline $\begin{array}{l}\text { McMaster- } \\
\text { Cart cataiog }\end{array}$ & $-9327 \mathrm{~T} 221$ & 9327 T231 & $9327 \mathrm{~T} 232$ & $9327 T 66]$ & $9246 \mathrm{~T} 62$ \\
\hline Description: & $\begin{array}{l}\text { Crimped } \\
\text { Metal } \\
\text { Wire } \\
\text { Cloth }\end{array}$ & $\begin{array}{c}\text { Crimped } \\
\text { Metal Wire } \\
\text { Cloth }\end{array}$ & $\begin{array}{l}\text { Crimped } \\
\text { Metal Wire } \\
\text { Cloth }\end{array}$ & $\begin{array}{c}\text { Crimped } \\
\text { Metal Wire } \\
\text { Cloth }\end{array}$ & $\begin{array}{c}\text { Galvanized } \\
\text { Steel } \\
\text { Welded } \\
\text { Mat }\end{array}$ \\
\hline Material: & $\begin{array}{l}\text { Plain } \\
\text { Sireel }\end{array}$ & Plain Steel & Plain Steel & $\begin{array}{l}\text { Type } 304 \\
\text { Stainless }\end{array}$ & $\begin{array}{l}\text { Galvanized } \\
\text { Steel }\end{array}$ \\
\hline Space Size: & $4^{+}$ & 2 & $1 \frac{1 / 2}{2}$ & $2^{\prime \prime}$ & $2^{n}$ \\
\hline Diameler: & $0.250^{n}$ & $0.120^{\circ+1}$ & $0.135^{m}$ & $0.120^{m}$ & $0.100^{n}$ \\
\hline
\end{tabular}

The measuring lead was terminated in a $50 \Omega$ resistor to prevent oscillations between the grid impedance and the capacitance of the coaxial cable used to carry the signal to the oscilloscope. The wire from the point being measured to the terminated measuring cable would have an inductance of no more than $1 \mu \mathrm{H}$, which taken with the $50 \Omega$ impedance of the cable would imply a measuring time constant, $L / R$, of only about $0.02 \mu \mathrm{s}$.

The grids were tested first by injecting current from a low voltage pulse generator and later by injecting current from a higher voltage surge generator. The low voltage machine employed a $5 \mu \mathrm{F}$ capacitor charged to about $300 \mathrm{~V}$ and discharged through an internal waveshaping circuit. This machine produced double exponential type currents with a front time of about $20 \mu \mathrm{s}$, a decay to half value of about $200 \mu \mathrm{s}$ and a peak amplitude of about $3 \mathrm{~A}$.

The high voltage machine employed a capacitor charged to about $30 \mathrm{kV}$ and produced double exponential type currents with a front time of about $4 \mu \mathrm{s}$, a decay to half value of $80 \mu \mathrm{s}$ and a peak current amplitude of about 2360 A. Figure 5 displays a high current waveform used for Grid \#1.

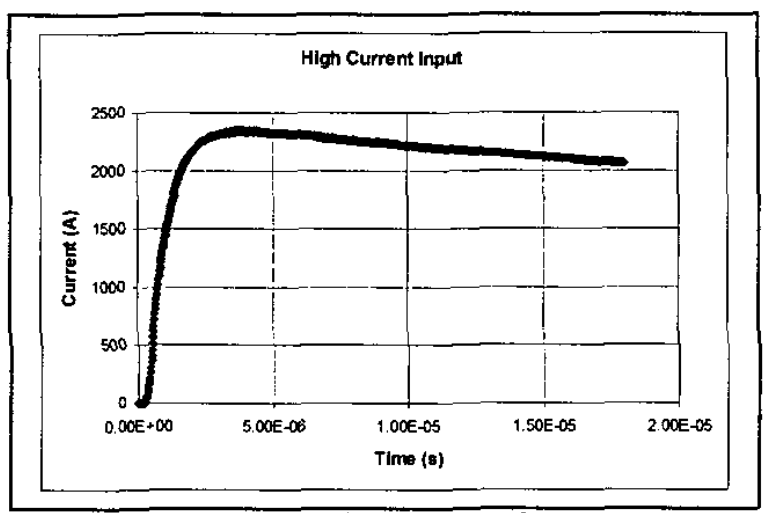

Figure 5. High current waveform

\section{VALIDATION TEST RESUlTS}

Results of testing show good agreement between simulated and measured voltages. Figures 6 and 15 show simulated and measured voltage in the grids.

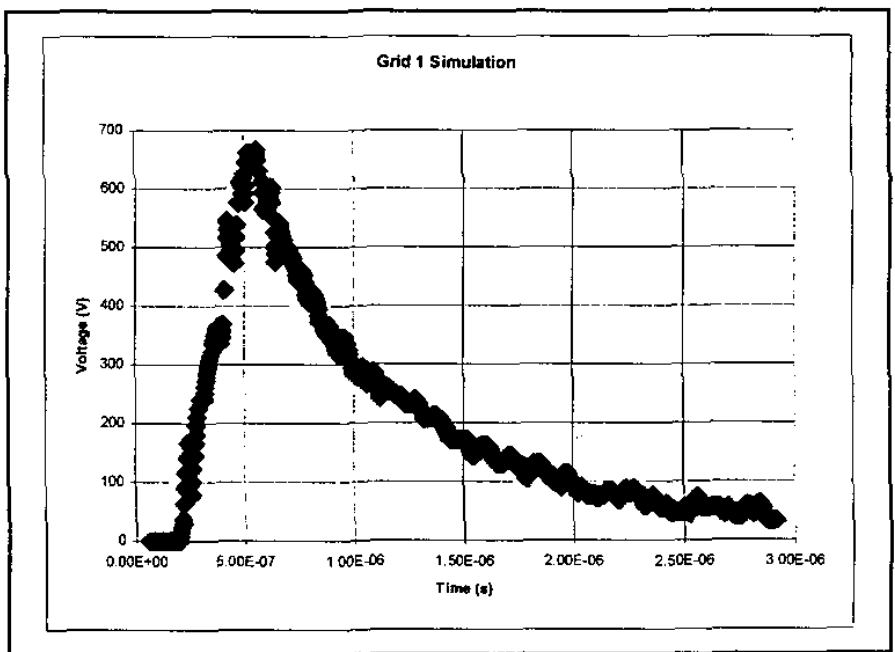

Figure 6. Simulated voltage profile across Grid \#1

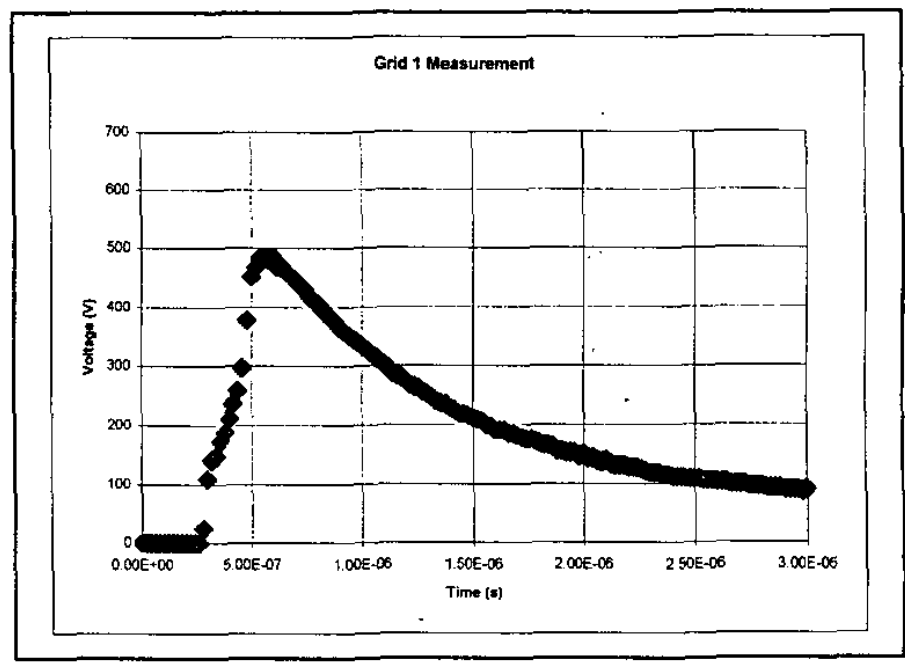

Figure 7. Measured voltage profile across Grid \#1 


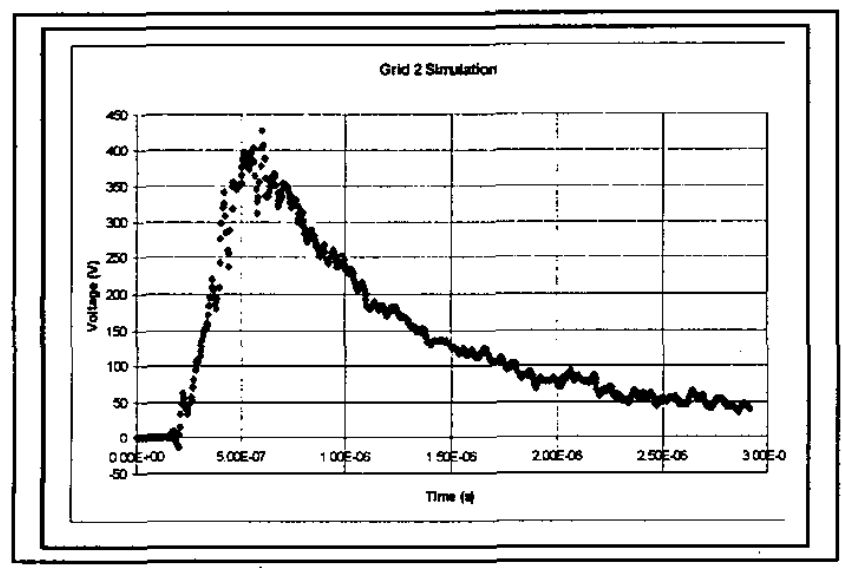

Figure 8. Simulated voltage profile across Grid \#2

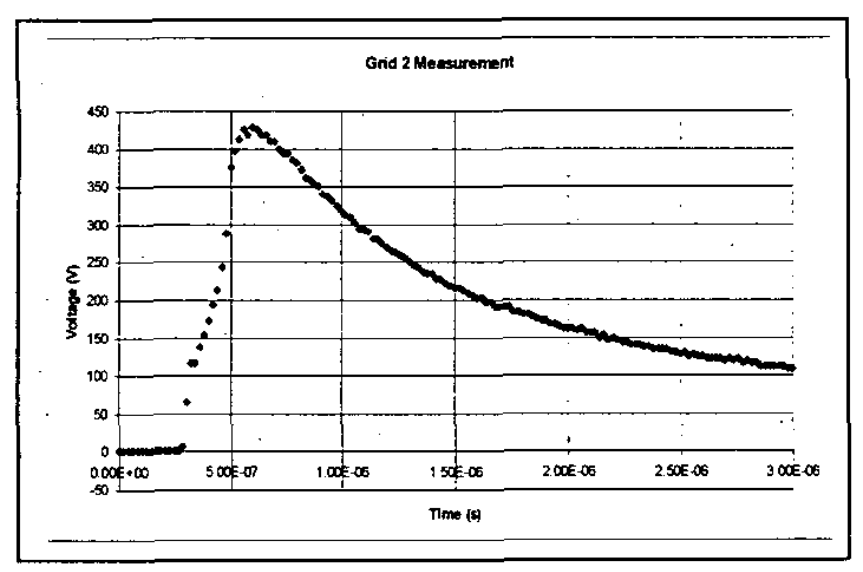

Figure 9. Measured voltage profile across Grid \#2

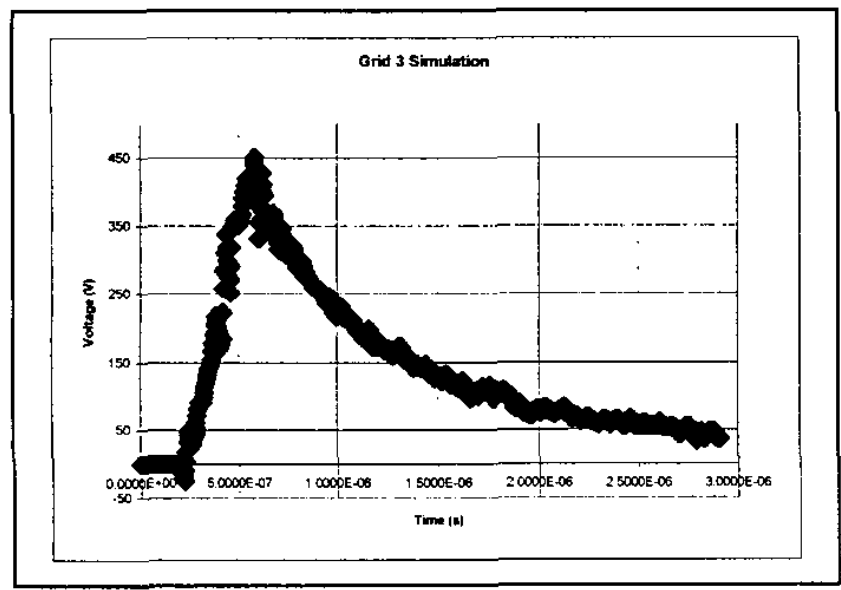

Figure 10. Simulated voltage profile across Grid \#3

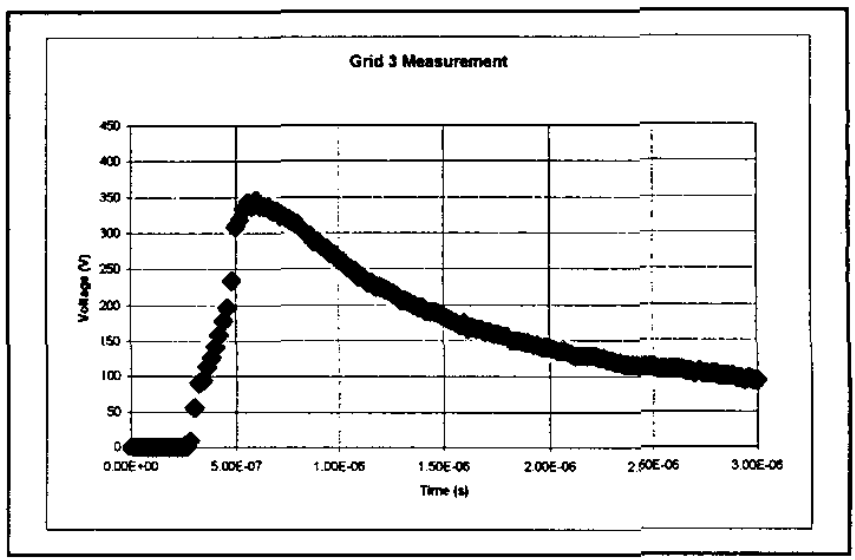

Figure 11. Measured voltage profile across Grid \#3

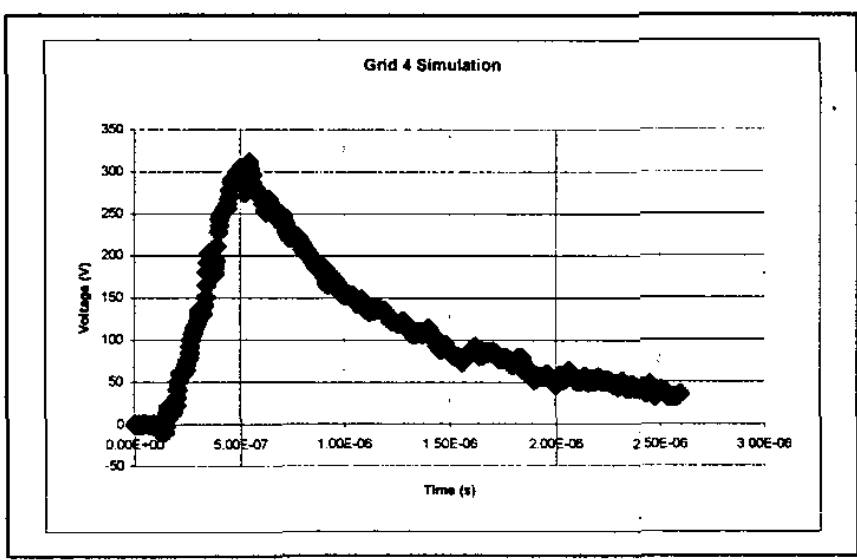

Figure 12. Simulated voltage profile across Grid $\# 4$

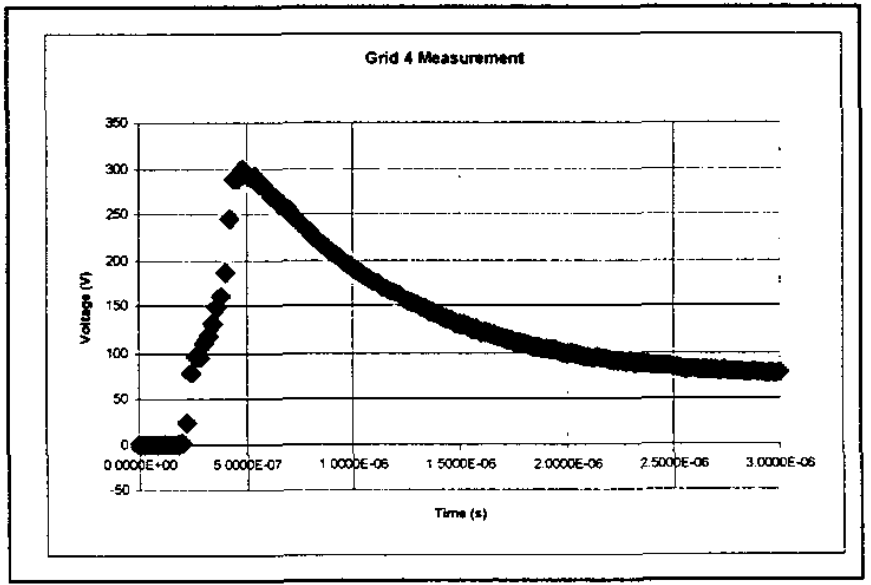

Figure 13. Measured voltage profile across Grid \#5 


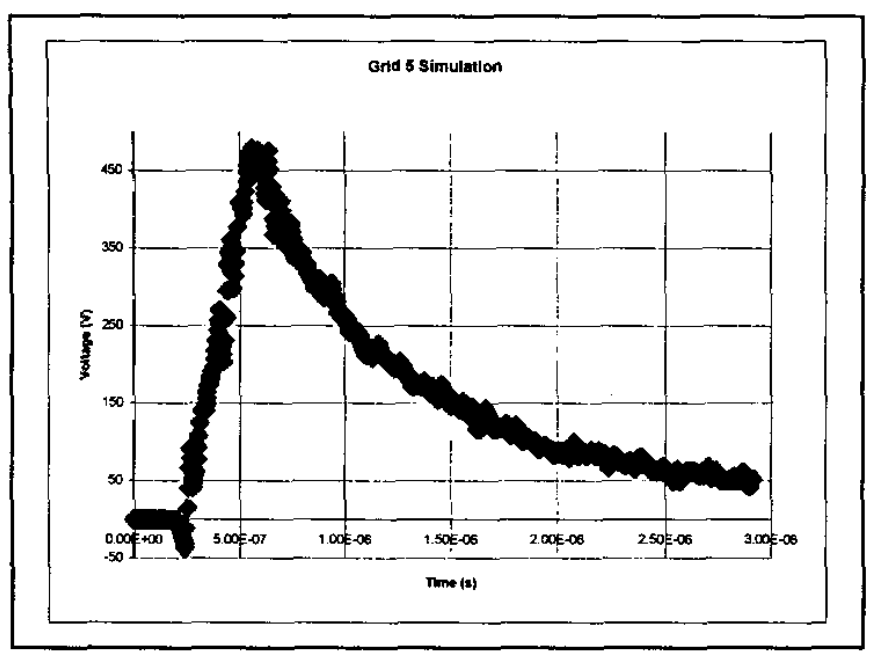

Figure 14. Simulated voltage profile across Grid \#5

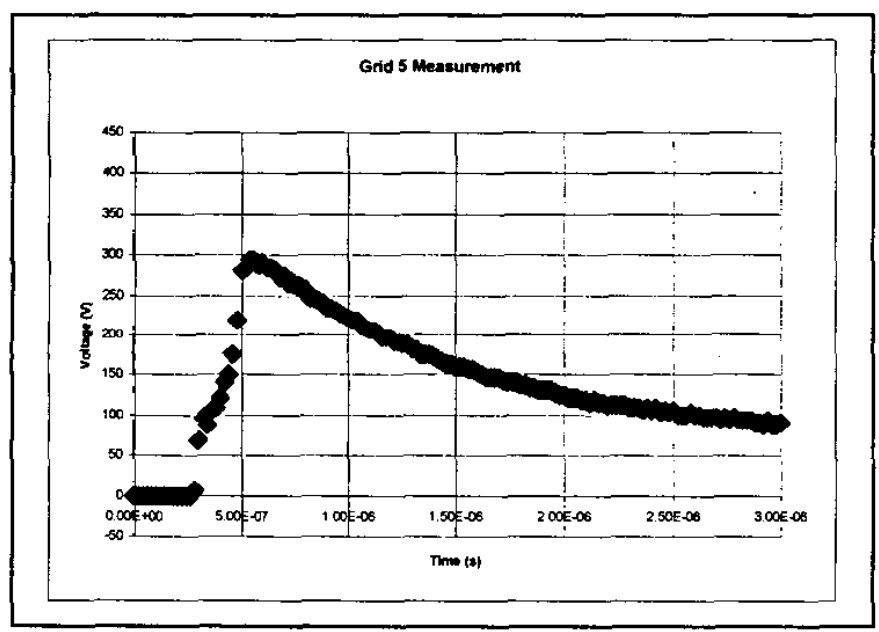

Figure 15. Measured voltage profile across Grid \#5

Even though the ECLM model only modeled resistance and self-inductance for the steel segments, simulated voltage profiles match the characteristic details found in the measured profiles. Simulations match or exceed measured voltages without incorporating mutual inductance in the simulations.
A summary of simulations and measurements is found in Table II.

TABLE II. SUMMAR Y OF HIGH CURRENT RESULTS

\begin{tabular}{|l|l|l|l|}
\hline & $\begin{array}{l}\text { SIMULATED } \\
\text { VOLTAGE }\end{array}$ & $\begin{array}{l}\text { MEASURED } \\
\text { VOLTAGE }\end{array}$ & $\begin{array}{l}\text { PERCENT } \\
\text { DIFFERENCE }\end{array}$ \\
\hline GRID \#1 & $667 \mathrm{~V}$ & $473 \mathrm{~V}$ & $29 \%$ \\
\hline GRID \#2 & $428 \mathrm{~V}$ & $426 \mathrm{~V}$ & $0.5 \%$ \\
\hline GRID \#3 & $451 \mathrm{~V}$ & $347 \mathrm{~V}$ & $24 \%$ \\
\hline GRID \#4 & $311 \mathrm{~V}$ & $300 \mathrm{~V}$ & $3.5 \%$ \\
\hline GRID\#5 & $479 \mathrm{~V}$ & $294 \mathrm{~V}$ & $39 \%$ \\
\hline
\end{tabular}

\section{CONCLUSIONS}

Test results showed excellent agreement with simulations. In all cases simulations were of equal or higher voltage than voltage measurements indicating that the lightning circuitry model is conservative. Agreement between simulations and measurements was much better than expected with a maximum deviation of $39 \%$ and with the results of 2 of the 5 grids matching with less than a $5 \%$ difference.

\section{ACKNOWLEDGMENT}

This research was funded as a Plant Directed Research and Development project for BWXT Pantex, LLC under DOE contract DE-AC04-00AL-66620.

\section{REFERENCES}

[1] Koone, Neil, and Condren, Brian, "PSpice model of lightning strike to a steel reinforced structure," Radio Frequency Power in Plasmas: $15^{\text {th }}$ Topical Conference on Radio Frequency Power in Plasmas. edited by Cary B. Forest, American Institute of Physics, 2003, pp. 419-422.

[2] Sandia National Laboratories, facility tranfer impedance reports, unpublished.

[3] Fisher, F. A., "Circuit model validation tests," LT-03-2214, Lightning Technologies Inc., 26 September 2003. 